\title{
ARTICLE
}

\section{Thought Experiments in Law}

\section{Special Issue on Experimental Legislation in Times of Crisis, Sofia Ranchordas \& Bart van Klink (eds.)}

\author{
Gabriel Doménech-Pascual*
}

\begin{abstract}
Thought experiments have been widely used in virtually all sciences and humanities. Law is no exception. We can find countless instances of such experiments in both the legal practice and the legal theory. However, this method has hardly been studied by legal scholars, which contrasts with the vast literature devoted to it in other fields of knowledge. This article analyses the role that some thought experiments - those where an imaginary legal change is made, and its social effects are observed - may play in law. In particular, we show why these empirical legal thought experiments might be useful for the practice and theory of law, the main principles for conducting them and how the law deals with them.
\end{abstract}

Keywords: legal empirical studies, legal methodology, philosophy of law, thought experiments.

\section{Introduction}

An experiment is the kind of scientific experience in which some change is deliberately provoked, and its outcome observed, recorded and interpreted with a cognitive aim' (Bunge, 1998, 281).

Experiments are the best available method for making causal inferences. If, after introducing a variation in a real object and observing a certain outcome in it, the same result is not seen in another identical object where, all else being equal, no such change was made, one can reasonably conclude that this variation caused that result. Mere observation, on the contrary, usually only provides correlations. Since the observer does not control the reality under study, he or she can never be sure that the observed phenomena have been caused by some variables and not by others that escape his or her control.

* Dr. Gabriel Doménech-Pascual, PhD is full professor of Administrative Law at the University of Valencia, Spain. I thank Bart van Klink, Sofia Ranchordas, Alba Soriano, María José Añón, Pablo de Lora, Diego Papayannis, Arturo Muñoz, Violeta Ruiz, Pedro Herrera, Viviana Ponce de León, Maximiliano Marzetti, and two anonymous referees for their useful and thoughtful comments. All remaining errors are mine. 
For example, several observational studies have shown that, on average, defendants represented by attorneys - whose intervention was not mandatory in the criminal proceedings under study - received more severe sanctions than defendants who had not enjoyed legal counsel. Some authors have pointed to the poor performance of their duties by many of those attorneys as one of the possible causes (Burrus \& Kempf-Leonard, 2002). Nevertheless, there could also be another explanation: the existence of a kind of 'selection bias'. It is possible that the defendants who were more likely to be punished more severely were also the ones who most frequently got legal counsel (Green \& Thorley, 2014). An experiment could clarify this question. Let us imagine that, for a few years, the selection of defendants to be represented by attorneys was made by flipping a coin. This would arguably ensure that the distribution of the probability of receiving serious sanctions would be similar both in the (experimental) group of those receiving legal counsel and in the (control) group formed by the rest of the defendants. Therefore, if after a while it was observed that the prevalence of sanctions was higher in one of the two groups, all else being equal, the difference could be causally attributed to the intervention (or non-intervention) of attorneys.

Experiments have played a major role in the development of natural sciences. In the field of social sciences and humanities, they have been much less relevant, although things are changing. In psychology, for example, this is surely the most widely used empirical method nowadays. In economics, experimental studies have substantially proliferated during the last decades (see Fréchette \& Schotter, 2015; Banerjee \& Duflo, 2017; Schram \& Ule, 2019). And even in areas such as linguistics, philosophy, political science and law, they are being conducted more and more frequently (see, for instance, Druckman et al., 2011; Greiner \& Matthews, 2016; Knobe \& Nichols, 2017; Fisher \& Curtis, 2019).

Experiments are also being increasingly employed outside academia. On the one hand, they are revolutionizing how businesses make decisions (Luca \& Bazerman, 2020). The so-called $A / B$ tests provide a good example. By means of randomized controlled experiments, usually conducted online, two variants of the same product or service (e.g., two versions of the same webpage) are compared (e.g., randomly displayed to the users) in order to determine which one produces the best outcomes (e.g., gets more user interactions). Companies like Google, Microsoft, Amazon, Facebook, Netflix, etc. run thousands of similar tests each year, in which millions of users unwittingly participate (Kohavi, Tang \& Xu, 2020). On the other hand, an increasing number of governments are carrying out field experiments in order to try or implement new policies and legal rules (Werner \& Riedl, 2019).

Two main factors have contributed to the current boom of experiments: their growing benefits and their declining costs. During the 20th and 21st centuries, there have been considerable advances in the methods, techniques and technologies for designing, conducting and analysing experiments. These advances have (i) substantially improved the information that experiments can yield, thereby increasing their expected benefits and (ii) drastically reduced the costs of carrying them out. It is no coincidence that experiments have massively proliferated in the digital economy. Online trials have generated and are still generating large returns 
for tech companies. The information on user behaviour produced by means of tests where high numbers of individuals participate is very reliable and useful for these firms, whereas the marginal cost of carrying those tests through the internet is very low.

In this article, we study a peculiar type of experiments, which we call 'empirical legal thought experiments'. After defining them (Section 2), we show why these experiments might be useful for the practice and theory of law (Section 3), what are the principles for conducting good empirical legal thought experiments (Section 4) and how the law deals with them (Section 5).

\section{Definition of Empirical Legal Thought Experiment}

There is no consensus about how to define a 'thought experiment'. There is an extremely diverse set of activities that might warrant and actually have been given that label (Stuart, 2020, 3). However, we can agree that all thought experiments share at least the two following common features: first, they are carried out in the imagination, in the 'laboratory of the mind'; second, a hypothetical scenario is thought, and a question related to it is asked, whose nature often depends on the area of knowledge involved. In both natural and social sciences, the question is usually what would happen in the situation described (i.e., an empirical question). In metaphysics, epistemology and philosophy of language, it is often asked how we should describe what would happen in that scenario (conceptual question). In ethics and aesthetics, the question is how to evaluate what would happen there, or what we should do (axiological or normative question) (Gendler, 2000, 25).

We are interested in empirical questions. For the purposes of this article, we define empirical thought experiments as the kind of scientific experience that takes place in an imaginary scenario, where some change is provoked and its outcome observed and interpreted with a cognitive aim. The term 'empirical thought experiment' (coined by Buzzoni, 2010) might seem a contradictio in terminis, but it is actually not. It arguably makes sense to call empirical those thought experiments that (i) try to test an empirical hypothesis (ii) by using pre-existing empirical evidence and (iii) might be useful to prepare a real experiment, insofar as they have the same purpose and logical structure as real experiments (Buzzoni, 2010). Moreover, this term enables us to distinguish such thought experiments from those aimed at testing conceptual, normative or axiological hypothesis.

Thought experiments are ubiquitous. They have been widely used by countless authors, from ancient times to the present, and have had an extraordinary impact in the development of virtually all sciences and humanities (see Frappier, Meynell \& Brown, 2013; Stuart, Fehige \& Brown, 2018).

In physics, we find, among many others Galileo's leaning tower of Pisa; Newton's rotating bucket and cannonball; Einstein's box and trains; Heisenberg's microscope; Schrödinger's cat, etc. (see Brown, 1993; Genz, 1999; Kühne, 2005). In philosophy, we have Searle's Chinese room; Nagel's bat; Wittgenstein's beetle-in-abox; Putnam's twin earth, etc. (see Häggquist, 1996; Behmel, 2001).

Many of the greatest works of political philosophy have been built upon 'macro thought experiments', such as Plato's Republic; Hobbes's state of nature; Rosseau's 
social contract; Rawls's original position and veil of ignorance, etc. (Miscevic, 2018).

In the field of ethics, we have, to cite only a few Foot and Thomson's trolley problem; Thompson's violinist; Nozick's utility monster; Carneades's plank; Fuller's Speluncean explorers; Singer's drowning child, etc. (Brun, 2018). The first formulation of the Kantian categorical imperative - act according to that maxim of your will that can always be valid at the same time and without contradiction as a universal law - is nothing else but a rule whose application requires carrying out a thought experiment, which involves comparing different possible states of the world and, in particular, checking in our imagination if the maxim of our will is susceptible to being generalized universally (Parfit, 2011, 285, 328, 329).

It has been argued that thought experiments are uncommon in economics (Shabas, 2018, 171). The formal models contained in most theoretical papers would certainly share some common features with thought experiments: (i) both describe an idealized and hypothetical scenario; (iii) there is a manipulation in it; (iii) the outcomes of this manipulation are observed and (iv) the aim is to explain real phenomena (Thoma, 2016). However, they also differ in various ways. Thought experiments take place purely in the imagination, and they need to be 'visualisable' in order to 'engage intuitions that are fairly universal'. They describe situations and employ reasoning patterns that are familiar to 'real people' and, therefore, the results are plausible, intuitive and credible for them. Formal models, on the contrary, represent highly abstract scenarios that are very hard to imagine, and their results are not derived by intuition, but 'by calculation, using pen and paper or a computer' (Thoma, 2016).

We do not agree with this opinion. As other authors have noted, the mental manipulation of the models that are widely used in economics might be considered as thought experiments. The same would apply to 'simulation experiments', which 'rest on automated iterations of formal algorithms' (Lenhard, 2018, who holds a different opinion). 'Thought experimenting is a form of mental modeling ... a species of reasoning rooted in the ability to imagine, anticipate, visualize, and re-experience from memory' (Nersessian, 2018, 309-310). Models build mental environments, imaginary worlds. These theoretical constructions represent social interactions by means of a set of variables and the relationships between them. By manipulating - in our minds - one of these variables or relationships, models allow us to isolate and explore their 'causal' effects on the other variables (see Mäki, 2005; Reiss, 2013; Rodrik, 2015, 21-25). There is not a difference of nature between formal models and 'classical' thought experiments. They are instances of the same thing. There is only a difference in the degree of abstraction, accuracy and logical consistency with which the hypothetical problem is described and the results are derived. Formal models represent problems in a very general, concise, unambiguous, transparent, rigorous and accurate way. And once the assumptions of the model are formulated in this way, the 'machinery of the mathematics' helps to draw logically consistent and accurate inferences, which could not be obtained without them (Hartmann \& Sprenger, 2011). The disadvantage of these models is that they are less visualisable and understandable by 'normal people' than typical thought experiments. That is why many economics (e.g., law and economics) pa- 
pers try to get the best of both worlds: they contain mathematical models in addition to examples that illustrate and help to understand them.

Countless thought experiments can also be found in legal theory. Let us remember, for instance, the Holmes's bad-man theory:

if you want to know the law and nothing else, you must look at it as a bad man, who cares only for the material consequences which such knowledge enables him to predict, not as a good one, who finds his reasons for conduct, whether inside the law or outside of it, in the vaguer sanctions of conscience. (Holmes, 1897, 459)

Let us also recall the method Jhering $(1891,323)$ claimed to use in order to make himself clear about the raison d'être of any legal institution: 'I think what would happen if that institution did not exist, and see what then becomes of the law in practical terms: the gaps that arise show me what the institution is there for'. ${ }^{1}$

Thought experiments are pervasive in the practice of law as well. For instance, when determining causation, courts often apply the so-called but-for-test, which entails a counterfactual thought experiment. Under this test, someone's conduct is to be considered the cause of an event if, but for that conduct, the event would not have occurred. 'The test instructs the factfinder to recreate an imaginative past, in which the factfinder eliminates the [conduct] and plays out an alternative (counterfactual) history' (Strassfeld, 1992, 346). Courts also conduct similar counterfactual inquiry when determining tort compensation. 'At the bottom, all determinations of tort damages imply a comparison between the actual world and a counterfactual one in which the defendant had not injured the plaintiff' (Strassfeld, 1992, 346). Another example is the 'Manhart test', applied by the Supreme Court of the United States of America to examine whether there is discrimination on the grounds of sex. It asks 'whether the evidence shows treatment of a person in a manner which but for that person's sex would be different'. ${ }^{2}$ Similarly, when examining whether procedural irregularities justify the annulment of a (legislative, administrative or judicial) decision under review, courts apply some kind of 'harmless error rule'. According to one of the several versions of this rule, 'an infringement of [procedural] rights results in the annulment of the decision taken at the end of the ... procedure at issue only if, had it not been for such an irregularity, the outcome of the procedure might have been different'. ${ }^{3}$

1 'Ich denke es mir hinweg und sehe zu, was dann in praktischer Beziehung aus dem Recht wird - die Lücken, die sich ergeben zeigen mir, wozu das Institut da ist.'

2 City of Los Angeles, Department of Water and Power v. Manhart, 435 U.S. 702, 711 (1978). See Dembroff, Kohler-Hausmann and Sugarman (2020).

3 Kamino International Logistics BV and Datema Hellmann Worldwide Logistics BV, Judgment of the European Court of Justice of 3 July 2014, Cases C-129 and 130/13, ECLI:EU:C:2014:2041, paragraph 79 . 
In spite of such pervasiveness, this method has hardly been analysed by legal scholars (however, see Mitchell, 2004; ${ }^{4}$ Del Mar, 2018a, 2018b, 20205). The present article tries to contribute to this analysis, by focusing on what might be called 'empirical legal thought experiments', which we define as those though experiments where a legal change is made, and its outcome observed and interpreted. Here we use both the terms 'legal change' and 'outcome' in a very broad sense. The former includes any variation in the world of legal phenomena: laws, statutes, administrative decisions, judicial decisions, contracts, testaments, how any of them are interpreted or applied, etc. The term 'outcome' refers to any consequence that the legal change in question may produce on social reality, namely, how it will influence, either directly or indirectly, the behaviour of the people actually or potentially affected by that variation; how legislatures, administrative authorities and courts will react to it; what will be the impact of those conducts on certain interests; whether and to what extent those changes will increase or decrease individual and social welfare, etc. ${ }^{6}$

Let us note that both legal scholars and legal practitioners sometimes conduct thought experiments that are not intended to immediately answer empirical questions, but conceptual or normative ones, like, for instance the following: In the light of some outlined facts, did Titius conclude a contract? Did he obtain an unjust enrichment? Should he be held liable for having caused an accident? Should torture be allowed under certain conditions? A famous example of a normative legal thought experiment is Mrs. Sorenson's case on 'market share liability' presented by

4 Taking the Enron case as an example, Mitchell (2004) critically examines the use of single-case studies to develop causal explanations for legal events. He shows that such a method makes it necessary to conduct counterfactual thought experiments to test the causal hypothesis at issue. He also proposes several normative criteria to conduct these experiments, namely transparency; counterfactuality of the proposed antecedent; consideration of competing hypothesis; theoretical and statistical reasonableness of the proposed causal claim; cotenability and counterfactual minimalism and projectibility.

5 In his fundamental contribution, Del Mar (2020) examines how 'artefacts' and related processes of imagination are valuable in legal reasoning and, in particular, in adjudication, as they enable 'activities of inquiry' [i.e., they might provide useful information]. He defines artefacts as forms of language that signal their own artifice, thereby capturing our attention, and call on us to participate in activities and processes of imagination. Del Mar focuses on four types of artefacts: fictions, metaphors, figures and scenarios. The last would be the closest artefact to thought experiments. Del Mar defines scenarios as 'short, fictional narratives, which are crafted, e.g. by advocates, in order to show the absurdity of a rival argument, or by judges to test the implications of a certain proposed ruling' ' $[\mathrm{B}] \mathrm{y}$ imagining with and thanks to scenarios, judges and others involved in the adjudicatory context can generate normative insight: they can generate insight as to what values, vulnerabilities and interests might be at stake in a case and in others potentially like it in the future.' Del Mar points out the epistemic importance of the emotions simulated and produced by scenarios: 'without experiencing emotions, or engaging in sensory or kinesic simulation, we would not be able to make insights into potentially relevant values, vulnerabilities and interests'. In fact, he considers that, "[i]n many respects, we can think of scenarios as "emotion experiments" rather than "thought experiments".

6 On the kinds of consequences of legal decisions, which eventually should be taken into consideration in legal reasoning by scholars, practitioners and decision-makers, see MacCormick (1983, 246-254); Mathis (2011, 5-6). 
Dworkin $(2006,143){ }^{7}$ In the legal literature on causation, we find countless instances of conceptual thought experiments, where an imaginary case is described and the question of whether a certain person can be considered as having caused the harm at issue is raised (e.g., Hart \& Honoré, 1985; Moore, 2009).

In the present article, we are not going to analyse normative or conceptual legal thought experiments, but only empirical ones. However, it must be noted that the lines between these three types are sometimes blurred. For instance, one could consider whether some hypothetical regulation constitutes an expropriation ('regulatory taking'). This might seem a conceptual thought experiment, but it also entails a normative one, insofar as the answer has legal implications, namely regarding whether the affected owners are entitled to compensation. Moreover, this answer may depend on the factual consequences such compensation might have, e.g., on the incentives it could create for owners in similar future cases.

\section{Usefulness of Empirical Legal Thought Experiments}

\subsection{Legal Thought Experiments Are Necessary for Conducting Legal Real Experiments} It is said that thought experiments may serve different cognitive purposes: confirming or disconfirming hypothesis or theories; illustrating theoretical claims; generating new ideas; planning real experiments; substituting real experiments, when these are not possible or too costly to be carried out, etc.

We want to point out, first, that thought experiments are necessary for - and, in fact, always precede - real experiments. As Buzzoni (2018, 333, 334) has noted, the former are 'the condition of the possibility of [the latter] because, without the a priori capacity of the mind to reason counterfactually, we could not devise any hypothesis and would be unable to plan the corresponding real experiments that should test it'. 'All real experiments may also be thought of as realizations of thought experiments; conversely, all empirical thought experiments must be conceivable as preparing and anticipating real experiments.'

This point can be illustrated with the way in which Kahneman and Tversky produced their groundbreaking empirical research, which challenged the rationali-

7 'Mrs. Sorenson suffered from rheumatoid arthritis and for many years took a generic drug - inventum - to relieve her suffering. During that period, inventum was manufactured and marketed under different trade names by eleven different pharmaceutical companies. In fact, the drug had serious and undisclosed side effects, of which the manufacturers should have known, and Mrs. Sorenson suffered permanent cardiac damage from taking it. She was unable to prove which manufacturer's pills she had actually taken, or when, and of course unable to prove which manufacturer's pills had actually injured her. She sued all drug companies who had manufactured inventum, together, and her lawyers argued that each of them was liable to her in proportion to its share of the market in the drug over the years of her treatment. The drug companies replied that the plaintiff's request was entirely novel and contradicted the long-established premise of tort law that no one is liable for injury he has not been shown to have caused. They said that since Mrs. Sorenson could not show that any particular defendant had injured her or even manufactured any of the inventum she took, she could recover against none of them. How should lawyers and judges decide which side - Mrs. Sorenson or the drug companies - is correct in its claims about what the law actually requires?' 
ty assumption prevailing in modern economic theory, and revolutionized psychology, economics and other scientific disciplines. In Kahneman's own words,

Our method of research in those early Jerusalem days was pure fun. We would meet every afternoon for several hours, which we spent inventing interesting pairs of gambles and observing our own intuitive preferences. If we agreed on the same choice, we provisionally assumed that it was characteristic of humankind and went on to investigate its theoretical implications, leaving serious verification for later. This unusual mode of empirical research enabled us to move quickly. In a few giddy months we raced through more than twenty diverse theoretical formulations. (Kahneman \& Tversky, 2001, X)

Therefore, the greater the relevance of real experiments, the greater the importance of the thought experiments that are to be carried out to plan, prepare and execute the former. And it must be noted that, as we have already seen, such relevance has increased substantially over the last few decades, both in legal theory and policymaking.

Legal phenomena are susceptible to being theorized from very different perspectives. Experiments can be useful for a given legal theory insofar as it is concerned with causal relationships between facts, which is not always the case. Empirical methods do not seem to make much sense, for example, in a 'pure theory of law à la Kelsen' (1960), nor in a theory focused almost exclusively on the exegesis of what the legislature wanted when passing a new law.

On the contrary, they might play a major role in those theories focused on the study of interactions between law and social facts. Experiments are especially useful within the framework of pragmatic, consequentialist or instrumental conceptions of the law, according to which legal rules are to be assessed in terms of their practical effects. ${ }^{8}$ If we are interested in determining and understanding these effects, we could use this method with the aim of answering questions like the following: How might people respond to legal changes? How likely is that they respond in one way or another? To what extent do the consequences of a rule meet the preferences of the people involved?. Getting well-founded answers to these questions is of capital importance not only to understand the meaning of the legal rules under consideration, but also to evaluate the possibility of interpreting, applying and modifying them.

It is thus no surprise at all that the number of both laboratory and field experiments carried out by law and economics scholars has increased considerably over the past few years (see Arlen \& Talley, 2008; Hoeppner, 2014). One of the main undertakings of law and economics is the application of economic theory and methods to explain, predict and assess the effects of legal rules, and real experiments can be very useful to develop and test theories about how people respond to those rules. 
Something similar applies to policymaking and legislation. In order to strike a fair balance between all the legitimate interests at stake, legislatures and governments need information, as robust and reliable as possible, about the impact their policies might have on those interests. This information can be provided by either laboratory or field experiments conducted by those authorities. They can try out the legal rules or regulations at issue on a small scale and for a limited period, observe the outcomes and assess them, with the aim of finding the best solutions, which could be established more permanently. In addition to generating information, experimental regulations may facilitate legal changes by luring their opponents into a compromise, given the limited scope - ratione temporis and, eventually, ratione materiae and ratione personae - of the rules that are being tried out (see Mader, 1988; Horn, 1989; Morand, 1993; Maaß, 2001; Hummel, 2003; Doménech Pascual, 2004, 2005; Abramowicz, Ayres \& Listokin, 2011; van Gestel \& van Dijck, 2011; Gubler, 2014; Ranchordas, 2014).

\subsection{Usefulness of Independent Empirical Legal Thought Experiments}

Real experiments provide more reliable information than thought experiments, but they are also more expensive or, sometimes, even impossible to conduct. That is why it is often not worth the effort to perform the former, but just to carry out 'independent' thought experiments, which are not intended to plan and execute any posterior real test. ${ }^{9}$

It must be pointed out that empirical thought experiments might still provide valuable information, that is to say, improve our understanding of legal phenomena. One of the most debated philosophical questions about these experiments is how they can increase understanding (Stuart, 2018) and generate new empirical knowledge, despite not involving new experience. It has been argued, in this regard, that thought experiments are arguments. They rearrange, reconfigure or extend pre-existing knowledge or data that we already have (Norton, 1991; Nersessian, 2018). 'In thought experiments we gain new information by rearranging already known empirical data in a new way and drawing new inferences from them or by looking at these data from a different and unusual perspective' (Brendel, 2004, 95; see also Brendel, 2018). They have been thus characterized as 'intuition pumps' (Dennett, 2013), that enable us to extract information from 'our heads'.

In a similar vein, it has been stated that thought experiments

anticipate a hypothetical experimental situation so that, on the basis or previous knowledge, we are confident that certain interventions on the experimental apparatus will modify some of its aspects (or variables) with such a degree of probability that the actual execution of the experiment becomes superfluous. (Buzzoni, 2013, 97)

9 As Buzzoni $(2018,335)$ points out, 'many thought experiments are as important as they are exactly because we are either technically incapable of realizing them or unwilling to carry out the corresponding real experiments, even though we have good reasons to regard them as in principle realizable'. 
They are 'scientifically useful and reliable because we presuppose that, if they were realized, the sequence of events that they describe according to causal connections which we assume to be operative in the real world, would occur in the way they anticipate, and would lead to the consequences that they predict' (Buzzoni, 2018, 335). Both types of experiments are therefore complementary, as that 'previous knowledge' or 'causal connections which we assume to be operative in the real world' come mostly from experimental evidence.

Some authors have raised the objection that we cannot learn anything from imagination, as we consciously and deliberately control what goes into the content of any act or process of imagining. However, as Del Mar (2020) has noted, we might be surprised by and learn from imagination [e.g. a thought experiment], because 'there are less-than-conscious and less-than-deliberate aspects' in these acts and processes.

Besides being much less costly than real experiments, 'independent' legal thought experiments may thus still be useful for both legal theory and practice. If properly designed, they can extract valuable information from previous theories and empirical evidence. The better both the experiment and this background knowledge are, the better that information might be.

That is why, nowadays, empirical legal thought experiments can arguably provide more robust information than ever. The explanation is simple. Thanks to the development of several disciplines (law and economics, behavioural law and economics, sociology of law, empirical legal studies, political science, etc.), our 'background' knowledge about the real effects of legal rules has never been as broad, profound and supported by empirical evidence as now. This can make the thought experiments based on it also more reliable than ever. And we may well expect that this reliability will continue to increase, as said background knowledge will continue to improve over the coming decades.

Unfortunately, many legal scholars and practitioners (judges, lawyers, legislators, etc.) still have an overly formalistic conception of law, and do not always consider sufficiently the practical effects of legal rules. They therefore do not carry out as many thought experiments as they probably should. Sometimes, when evaluating legal solutions, they do not try to imagine the real consequences to which they could lead. Other times, they do consider those effects, but in a superficial and myopic way, without taking sufficient account of previous theoretical and empirical studies that would allow them to improve the accuracy of their predictions in that regard.

\section{Principles of Good Empirical Legal Thought Experiments}

Real experiments are realizations of thought experiments. Therefore, both have the same structure, i.e. the same operational-methodological traits: both ask questions about the observable reality and its 'laws'; both try to answer those questions by observing what happens if we modify some variables in a controlled way and a given scenario, with the aim of establishing whether there is a relation of dependence between them; both do that in an idealized way, so that the meaning of both 
must always be interpreted, etc. (Buzzoni, 2013, 97-98). ${ }^{10}$ Hence, the principles for the former experiments might be applied to the latter ones (Wilson, 2016; Stuart, 2020).

\subsection{Simplicity}

Thought experiments, like models, are idealizations (Reiss, 2018). They represent the reality in a simplified way, by means of a few variables and assumptions. Simplification is useful and even necessary in order to 'identify a cause-effect relationship by isolating it from other confounding factors' (Rodrik, 2015, 180). It must be underlined that there is no unique correct way of representing reality in that regard. It all depends on the purpose of the experiment, on which theory it tries to test, on which causal relationships it aims to illustrate, establish or refute, etc. These experiments do not try to explain the whole reality, but only isolate one causal relationship, often the 'critical' or 'dominant causal mechanism or channel at work' in some phenomenon (Rodrik, 2015, 85). Therefore, the degree of simplification of legal thought experiments - i.e. the variables to be used and the assumptions to be made - depends crucially on their goal and, in particular, on the hypothesis at issue. In general, thought experiments should be as simple as possible. Additional variables or complications ought to be introduced into them only if they are strictly necessary to test the target hypothesis. The commandment would be 'Make your model [i.e. thought experiment] simple enough to isolate specific causes and how they work, but not so simple that it leaves out key interactions among causes' (Rodrik, 2015, 213).

Let us illustrate this point with an example. In order to criticize the Posnerian thesis according to which economic efficiency explains tort law, Weinrib (1989, 506-509) points out that this thesis does not explain why the compensatory damages to be paid by the injurer equal the loss suffered by the victim. Posner, argues Weinrib, provides economic reasons for taking a sum of money from the injurer and giving it to the victim; this rule would induce the former to take efficient precautions, but he does not account for setting this sum at a level that makes the victim whole. With the aim of showing that this rule is not justified for efficiency reasons and, therefore, refuting the Posnerian explanation of tort law, he runs the following thought experiment:

Assume ... that an expenditure by the defendant of $\$ 100$ will avert a $\$ 1000$ injury that has a $25 \%$ chance of occurring ... we must ask what figure is such that a $25 \%$ chance of being liable to pay it will induce a rational actor to expend $\$ 100$. The answer is 'any figure over $\$ 400$ '. A $25 \%$ probability of having to pay more than $\$ 400$ will induce a rational defendant to take precautions costing $\$ 100$.

10 With regard to economic models, Rodrik $(2015,24)$ considers that 'the gulf between real experiments carried out in the lab (or in the field) and the thought experiments we call "models" is less than we might have thought'. 
Therefore, in order to induce potential injurers to take efficient precautions, it is not necessary to mandate damages equal to the victim's loss (here, \$1000), but damages of any sum greater than the costs of such precautions divided by the probability of causing an accident if they are not taken (here, $\$ 100 / 0.25=\$ 400$ ).

There are many simplifications and implicit assumptions in this argument: potential injurers are rational; they maximize their expected utility; they are not judgment proof, etc. One of these assumptions is really critical here: ${ }^{11}$ potential injurers, victims and courts have perfect information. All of them accurately know the costs and benefits of precautions, the probability of causing an accident, the magnitude of the losses caused by accidents, etc. In reality, however, it rarely happens. They usually commit errors when estimating those factors. Once that unrealistic assumption is removed, one can see that there are good economic reasons for the abovementioned typical tort remedy, which is more efficient than that suggested by Weinrib.

Indeed, let us suppose that potential injurers make mistakes when calculating the probability of causing an accident. Some underestimate it by 0.05 , whereas others overestimate it by 0.05 . Note that if they were forced to pay $\$ 401$ in the event of an accident, no 'underestimator' would take efficient precautions (i.e. due care), since the private expected cost of omitting them $(\$ 401 \times 0.2=\$ 80.2)$ would be less than that of taking them (\$100). Only 'overestimators' would do so, since only for them the expected cost of omitting them $(\$ 401 \times 0.3=\$ 120.3)$ would exceed that of adopting them (\$100). On the contrary, if the typical tort remedy applies, every potential injurer will take due care. Even 'underestimators' will do so, since for them the private expected cost of omitting it $(\$ 1000 \times 0.2=\$ 200)$ is notably higher than that of taking it (\$100). One can see that this second thought experiment, based on more realistic assumptions than the former, supports the efficiency thesis.

\subsection{Internal Validity. Consistency}

The internal validity of an experiment is the extent to which it enables one to make causal inferences, i.e. the extent to which it may rule out that the outcomes observed (variations in the dependent variables) are caused by factors (omitted variables) different from the experimental treatment (changes made in the independent variables). In order to ensure such validity, we need a control object, identical to the experimental object, where those changes are not made. The problem of experiments where the research subjects are real human beings is that there are no identical individuals, so that the differences observed in the experimental and the control objects after the modifications are introduced might be caused not by these modifications, but by the differences between the individuals, i.e. by omitted variables. In order to solve this problem, researchers use different techniques. For example, they experiment with sufficiently large samples or groups of individuals with similar characteristics. Moreover, subjects are allocated to the experimental or the control group randomly. It ensures that the distribution of omitted variables

11 As Rodrik $(2015,27)$ notes, 'an assumption is critical if its modification in an arguably more realistic direction would produce a substantive difference in the conclusion produced by the model'. 
tends to be similar in both groups and, therefore, that these variables do not influence the outcomes.

When conducting independent thought experiments, by contrast, we just may imagine that all the subjects involved are identical, if we so wish. This is a distinctive feature of this kind of experiments. That is why they do not need to be randomized in order to ensure their 'internal validity'. While real experiments are to be controlled by means of physical, often imperfect, manipulations, thought experiments employ assumptions in order to neutralize confounding factors and isolate causal relations. Here, the experimenter just assumes, either explicitly or implicitly, that the necessary conditions are met. That is why, paradoxical as it may sound, a thought experiment can usually provide more 'tight' controls and isolations than a real one, as in the former case these only need to be imagined (see Mäki, 2005, 308-309).

The most important requirement of thought experiments, when it comes to ensure their internal validity, is their consistency. The outcomes of the experiment are to be coherent with the assumptions - i.e. the background knowledge - explicitly or implicitly made by the experimenter. That is, those outcomes must logically follow from the experimental changes, given these assumptions.

This does not always happen. The intuitions thought experiments 'pump out' are not always reliable and correct, i.e. logically supported by the relevant assumptions and previous knowledge, but fallacious. The imaginary scenarios of these experiments are sometimes depicted in a such a - fancy, picturesque, embellished, unfamiliar, outlandish, ambiguous, distracting, tricky, etc. - way that they mislead us into producing intuitive but wrong answers to the questions being posed (Brendel, 2004; Dennett, 2013; Stuart, 2018, 290). Eliminating unnecessary complications and making the relevant assumptions explicit can help prevent this problem.

\subsection{Generalizability}

Given their stylization, both real and thought experiments pose similar problems of 'external validity'. This term refers to the extent to which the outcomes of an experiment conducted under some specific circumstances might be generalized, i.e. extended to other circumstances (e.g., people, situations, times, etc.). The more generalizable the results, the more useful the experiment.

This generalizability depends crucially on the resemblance between the conditions under which the experiment is conducted and the circumstances to which the conclusions of the experiment are extended. The more similar in their most relevant aspects those conditions and circumstances are, the more generalizable the experiment will be.

\subsection{Reproducibility}

Scientific research should be reproducible in order to ensure its reliability. This reproducibility refers to different aspects. Methods reproducibility 'refers to the provision of enough detail about study procedures and data so the same procedures could, in theory or in actuality, be repeated' by other researchers. Results reproducibility (or replicability) 'refers to obtaining the same results from the conduct of an independent study whose procedures are as closely matched to the original exper- 
iment as possible'. Inferential reproducibility refers to the 'drawing of qualitatively similar conclusions from either an independent replication of a study or a reanalysis of the original study' (Goodman, Fanelli \& Ioannidis, 2016).

Empirical legal thought experiments should also be as reproducible as possible. The simpler the experiments are, the more clearly and precisely their conditions are spelt out and the better the background knowledge is, the more reproducible, reliable and compelling they will be. However, sometimes there is a trade-off between reproducibility and other principles, such as generalizability. For instance, when making some decisions, courts must consider how these decisions might affect certain rights and legitimate interests, given the specific circumstances of the case. If there are many interests at stake, the relevant circumstances are relatively complex and there is a great deal of uncertainty on the possible consequences of the decision at issue, the required thought experiment will inevitably not be very simple, reproducible and compelling. If it were, it would likely not be of much help in resolving the case.

\section{The Law of Empirical Legal Thought Experiments}

\subsection{Legal Principles, Proportionality and Empirical Legal Thought Experiments}

The law sometimes prescribes that a thought experiment is to be conducted. This may happen either because a legal provision explicitly establishes so or because the experiment is necessary for the application of legal principles.

Indeed, when applying legal principles and the so-called proportionality test, legislators and courts often need to carry out experiments, which almost always are imaginary, since real experiments are generally too expensive. As Alexy (1994, 2000, 2017) has shown, legal principles might be conceptualized as optimization requirements, which demand that something valuable be realized to the greatest extent possible given the legal and factual possibilities. The proportionality test is a logical consequence of legal principles being such optimization requirements. It consists of three subprinciples: suitability, necessity and proportionality stricto sensu. The suitability subprinciple precludes the adoption of measures that obstruct the realization of at least one principle without promoting any legitimate goal. The necessity subprinciple precludes the adoption of suitable measures that obstruct the realization of at least one principle if there is another measure that is at least equally suitable to promote the same legitimate goal, while undermining the realization of that principle to a lesser extent. According to the subprinciple of proportionality stricto sensu, the benefits of promoting the legitimate goal must exceed the costs of non-satisfaction for the principle at issue. Alexy considers that the subprinciples of suitability and necessity refer to optimization relative to the factual possibilities of satisfaction, whereas the subprinciple of proportionality stricto sensu concern the legal possibilities, which are determined essentially by opposing legal principles.

It must be noted, first, that the first two subprinciples preclude the adoption of Pareto inefficient measures, while the third one arguably precludes the adoption of Kaldor-Hicks inefficient measures. Second, we want to point out that all three 
subprinciples raise empirical questions, which might be - and often are - answered by means of empirical legal thought experiments.

Indeed, in order to apply the suitability subprinciple, one usually needs to conduct at least one thought experiment. One has to 'observe', in a hypothetical scenario identical to that of the case under consideration, whether the adoption of the measure in question would 'actually' advance a certain legitimate goal, and whether it would also obstruct the realization of the principle considered. For that purpose, it could be useful to carry out a counterfactual thought experiment, where it is imagined, in the same scenario, how the non-adoption of the measure at issue impacts the realization of that legitimate goal and of this legal principle.

When applying the necessity subprinciple, one has to observe, in an imaginary scenario identical to that of the present case, whether alternative measures advance some legitimate goal at least to the same extent as the measure under consideration, and whether they obstruct the realization of the principle at issue to a lesser degree.

Finally, in order to apply the subprinciple of proportionality stricto sensu, one has to carry out similar thought experiments to determine the expected costs and benefits of the measures under review for all the conflicting principles and legitimate interests at stake.

Whenever a legal principle is to be applied - for instance, to interpret a legal provision in one or several cases - thought experiments such as the ones we have just seen will have to be carried out. Since the application of legal principles is ubiquitous in legal decision-making and, in particular, in adjudication, so should these experiments be.

\subsection{Empirical Legal Thought Experiments in Legislation}

The law sometimes prescribes that a thought experiment is to be conducted in order to prepare and enact a legal rule. That is the case, for instance, of legal provisions that require a regulatory impact assessment to be carried out (Dunlop \& Radaelli, 2016). Before passing certain regulations, the competent public authorities must determine and assess the effects - the costs and the benefits - that these regulations may have. For this purpose, it is often necessary to conduct a thought experiment in which the regulation at issue is established and its effects on various aspects of social life are observed.

\subsection{Empirical Legal Thought Experiments in Adjudication}

Sometimes, judges also have to carry out similar experiments when adjudicating. This might occur at least in four types of cases.

First, some legal provisions explicitly provide that courts must make certain decisions on the basis of the immediate (micro-level) consequences that such decisions may have for the interested (and eventually third) parties. For instance, when deciding whether to adopt an interim measure or not, courts typically have to do the following: (i) Imagine an (experimental) scenario whose circumstances coincide with those of the case considered, and introduce a change in it, consisting of the adoption of the requested interim measure; (ii) Observe the consequences of this change for all the legitimate interests at stake; here, the relevant court 'must 
take account of the damage which the interim measure may cause'; ${ }^{12}$ (iii) Imagine a (control) scenario identical to the previous one, but in which no such change is made; (iv) Observe the outcomes for those interests; in particular, the court ought to consider whether the non-adoption of the requested interim measure 'would be likely result in irreversible damage to the applicant which could not be made good' if his or her claim ended up being upheld; ${ }^{13}$ (v) Compare the results that both scenarios yield; and (vi) Make the decision that probably produces the best results, namely that has the greatest net expected benefit for all the interests involved.

Second, in many legal systems, some courts (e.g. the German, Austrian, French, Italian and Spanish constitutional courts) have the power to make rulings with 'erga omnes effects' - i.e. applicable to an indefinite number of present and future cases - when reviewing and subsequently quashing statutory rules. In some cases, these courts may pass such general rulings even when the question on the validity of the statute at issue is tied to a specific controversy. These courts might then review and declare whether a legal rule applicable to a specific and real case is invalid not only for this case, but also for other actual or hypothetical cases. ${ }^{14}$

This makes it necessary for these courts to consider, by means of a thought experiment, what real consequences the statutory rules at issue may have in the abstract, in those future cases, e.g. whether said rules could have unacceptable 'chilling effects' on the exercise of some freedom under certain circumstances.

For instance, in the United States of America, statutes can be challenged and reviewed either 'facially' or 'as-applied'. In the first case, it is alleged that every application (i.e. possible interpretation) of the statute is unconstitutional and, therefore, this is to be 'facially' (entirely) struck down. In the second case, it is claimed that the statute is unconstitutional as applied in the specific case under consideration. Hence, if this challenge is successful, the court will invalidate only the particular application at issue (see Fallon, 2011). The Supreme Court has been sometimes reluctant to uphold facial challenges grounded on 'speculation about imaginary cases' ${ }^{15}$ and 'fanciful hypotheticals'. ${ }^{16}$ However, some kind of 'speculation' or consideration of the expected consequences of potential applications of the statute is unavoidable to decide on these facial challenges. ${ }^{17}$

Third, when making rulings that have precedential value, i.e. some kind of binding or persuasive effects for deciding subsequent similar cases, courts should - and in fact usually - consider the consequences those rulings might have in these hypothetical cases. ${ }^{18}$

Fourth, some legal principles (e.g., of equality and legal certainty) require courts to make decisions in a manner consistent with the decisions to be made by 9 November 1995, Case C-465/93, ECLI:EU:C:1995:369, paragraph 44.

17 See O'Grady (2011), who defines 'speculation' as 'hypothetical theories about human behavior that the statute's challengers argue will be triggered by the operation of the statute'.

18 See, for instance, the English contract law case, decided by the House of Lords, White \& Carter (Councils) v. McGregor (1962) SC (HL) 1, widely discussed by Del Mar (2018a, 2020, 8.II). 
the same or different courts in simultaneous or future similar cases. ${ }^{19}$ The courts, therefore, ought to pass rulings that could - and will probably - be generalized, i.e. applied to similar cases..$^{20}$ For that purpose, they should take account of the consequences those rulings might have in these other cases (see MacCormick, 1983, 2005). For instance, in the Atlanta judgement, where many companies were seeking interim relief against the application of a regulation, the European Court of Justice declared that [every] national court, when deciding on that relief,

must consider, on the one hand, the cumulative effect which could arise if a large number of courts were also to adopt interim measures for similar reasons and, on the other, those special features of the applicant's situation which distinguish from the other [individuals] concerned. ${ }^{21}$

In summary, various legal rules and principles (e.g., proportionality, equality and legal certainty) require courts to carry out thought experiments in order to find out and weigh the consequences their rulings may have, not only in the specific case being tried, but also in other similar cases.

\section{References}

Abramowicz, M., Ayres, I. \& Listokin, Y. (2011). Randomizing law. University of Pennsylvania Law Review, 159(4), 929-1005.

Alexy, R. (1994). Theorie der Grundrechte. Frankfurt am Main: Suhrkamp. There is an English translation by Julian Rivers: (2002). A theory of constitutional rights. Oxford: Oxford University Press.

Alexy, R. (2000). On the structure of legal principles. Ratio Juris, 13, 294-304.

Alexy, R. (2017). Proportionality and rationality. In V. C. Jackson \& M. Tushnet (Eds.). Proportionality. New frontiers, new challenges (pp. 13-29). Cambridge: Cambridge University Press.

Arlen, J. \& Talley, E. L. (2008). Experimental law and economics. Cheltenham: Edward Elgar.

Banerjee, A. V. \& Duflo, E. (Eds.). (2017). Handbook of field experiments (Vols. I and II). Amsterdam: North-Holland.

Behmel, A. (2001). Was sind Gedankenexperimente? Kontrafaktische Annahmen in der Philosophie des Geistes - der Turingtest und das chinesische Zimmer. Stuttgart: Ibidem.

Brendel, E. (2004). Intuition pumps and the proper use of thought experiments. Dialectica, 58(1), 89-108.

19 As Hurley $(1990,234)$ notes, in 'legal deliberation', for the sake of consistency and coherence, it is required that similar cases should be similarly resolved. Legal deliberation should thus be responsible to settled cases, 'both actual and hypothetical', just as scientific theorizing should be responsible to data. 'If in general the role of settled cases in [legal] deliberation is somewhat analogous to that of experimental data in scientific theorizing, then the role of hypothetical cases in particular may be regarded as somewhat analogous to that of thought experiments' [in science].

20 As MacCormick (1983) points out, "[t]o justify a decision in law is to present in its support universalized or universalizable reasons'.

21 Atlanta Fruchthandelsgesellschaft $\mathrm{mbH}$, Judgement of the European Court of Justice of 9 November 1995, Case C-465/93, ECLI:EU:C:1995:369, paragraph 44. 
Brendel, E. (2018). The argument view. Are thought experiments mere picturesque arguments? In M. T. Stuart, Y. J. H. Fehige \& J. R. Brown (Eds.). The Routledge companion to thought experiments (pp. 281-292). Abingdon-New York: Routledge.

Brown, J. R. (1993). The laboratory of the mind: Thought experiments in the natural sciences. London: Routledge.

Brun, G. (2018). Thought experiments in ethics. In M. T. Stuart, Y. J. H. Fehige \& J. R. Brown (Eds.). The Routledge companion to thought experiments (pp. 195-210). Abingdon-New York: Routledge.

Bunge, M. (1998). Philosophy of science. Volume II: From explanation to justification. New Brunswick: Transaction.

Burrus, G. Q. \& Kempf-Leonard, K. (2002). The questionable advantage of defense counsel in juvenile court. Justice Quarterly, 19(1), 37-68.

Buzzoni, M. (2010). Empirical thought experiments: A transcendental-operational view. Epistemologia, 33(1), 5-26.

Buzzoni, M. (2013). Thought experiments from a Kantian point of view. In M. Frappier, L. Meynell \& J. R. Brown (Eds.). Thought experiments in philosophy, science, and the arts (pp. 90-106). London: Routledge.

Buzzoni, M. (2018). Kantian accounts of thought experiments. In M. T. Stuart, Y. J. H. Fehige \& J. R. Brown (Eds.). The Routledge companion to thought experiments (pp. 327-341). Abingdon-New York: Routledge.

Del Mar, M. (2018a). Emotion experiments in legal thought. Critical Analysis of Law, 5(2), 178-195.

Del Mar, M. (2018b). Educating the legal imagination. Law and Method, October 2018.

Del Mar, M. (2020). Artefacts of legal inquiry. The value of imagination in adjudication. Oxford: Hart.

Dembroff, R., Kohler-Hausmann, I. \& Sugarman, E. (2020). What Taylor Swift and Beyoncé teach us about sex and causes. University of Pennsylvania Law Review Online, 169, 1-12.

Dennett, D. (2013). Intuition pumps and other tools for thinking. New York: W. W. Norton.

Doménech Pascual, G. (2004). Los experimentos jurídicos. Revista de Administración Pública, 164, 145-187.

Doménech Pascual, G. (2005). Descentralización administrativa y experimentalismo democrático. Cuadernos Constitucionales de la Cátedra Fadrique Furió Ceriol., 52-53, 43-67.

Druckman, J. N. et al. (Eds.) (2011). Cambridge handbook of experimental political science. Cambridge: Cambridge University Press.

Dunlop, C. A. \& Radaelli, C. M. (Eds.) (2016). Handbook of regulatory impact assessment. Cheltenham: Edward Elgar.

Dworkin, R. (2006). Justice in robes. Cambridge: Belknap.

Fallon, R. H. (2011). Fact and fiction about facial challenges. California Law Review, 99(4), 915-974.

Ferreres Comella, V. (2009). Constitutional courts and democratic values. A European perspective. New Haven, CT: Yale University Press.

Fisher, E. \& Curtis, M. (Eds.) (2019). Methodological advances in experimental philosophy. London: Bloomsbury.

Frappier, M., Meynell, L. \& Brown, J. R. (Eds.) (2013). Thought experiments in philosophy, science, and the arts. New York: Routledge.

Fréchette, A. \& Schotter, G. (Eds.) (2015). Handbook of experimental economic methodology. Oxford: Oxford University Press.

Gendler, T. S. (2000). Thought experiment. On the powers and limits on imaginary cases. New York: Garland.

Genz, H. G. (1999). Gedankenexperimente. Weinheim: Wiley.

Goodman, S. N., Fanelli, D. \& Ioannidis, J. P. A. (2016). What does research reproducibility mean? Science Translational Medicine, 8(341), 1-5. 
Green, D. D. \& Thorley, D. R. (2014). Field experimentation and the study of law and policy. Annual Review of Law and Social Science, 10, 53-72.

Greiner, J. \& Matthews, A. (2016). Randomized control trials in the united legal profession. Annual Review of Law and Social Science, 12, 295-312.

Gubler, Z. J. (2014). Experimental rules. Boston College Law Review, 55, 129-179.

Haack, S. (2005). On legal pragmatism: Where does the path of the law lead us? American Journal of Jurisprudence, 50, 71-105.

Häggquist, S. (1996). Thought experiments in philosophy. Stockholm: Almquist \& Wiksell International.

Hart, H. L. A. \& Honoré, T. (1985). Causation in the Law. Oxford: Oxford University Press.

Hartmann, S. \& Sprenger, J. (2011). Mathematics and statistics in the social sciences. In J. Zamora Bonilla et al. (Eds.). The SAGE handbook of the philosophy of social sciences (pp. 594-612). London: Sage.

Hoeppner, S. (2014). Experimental law and economics. In J. Backhaus (Ed.) Encyclopedia of law and economics. Springer: New York.

Holmes, O. W. (1897). The path of the law. Harvard Law Review, 10, 457-478.

Horn, H. D. (1989). Experimentelle Gesetzgebung unter dem Grundgesetz. Berlin: Duncker \& Humblot.

Hummel, K. (2003). Recht der behördlichen Regelungsexperimente. Berlin: Duncker \& Humblot.

Hurley, S. L. (1990). Coherence, hypothetical cases, and precedent. Oxford Journal of Legal Studies, 10, 221-251.

Jhering, R. v. (1891). Scherz und Ernst in der Jurisprudenz. Leipzig: Breitkopf \& Härtel.

Kahneman, D. \& Tversky, A. (Eds.) (2001). Choices, values, and frames. New York: Sage-Cambridge University Press.

Kelsen, H. (1960). Reine Rechtslehre. Mit einem Anhang: Das Problem der Gerechtigkeit. Wien: Franz Deuticke Verlag.

Knobe, J. \& Nichols, S. (2017). Experimental philosophy. The Stanford Encyclopedia of Philosophy. Retrieved from https://plato.stanford.edu/archives/win2017/entries/ experimental-philosophy/.

Kohavi, R., Tang, D. \& Xu, Y. (2020). Trustworthy online controlled experiments. A practical guide to A/B testing. Cambridge: Cambridge University Press.

Kühne, U. (2005). Die Methode des Gedankenexperiments. Frankfurt am Main: Suhrkamp.

Lenhard, J. (2018). Thought experiments and simulation experiments. Exploring hypothetical worlds. In M. T. Stuart, Y. J. H. Fehige \& J. R. Brown (Eds.). The Routledge companion to thought experiments. Abingdon-New York: Routledge.

Luca, M. \& Bazerman, M. H. (2020). The power of experiments. Decision making in a data-driven world. Cambridge: MIT Press.

Maa $\beta$, V. (2001). Experimentierklauseln für die Verwaltung und ihre verfassungsrechtlichen Grenzen. Berlin: Duncker \& Humblot.

MacCormick, N. (1983). On legal decisions and their consequences: From Dewey to Dworkin. New York University Law Review, 58, 239-258.

MacCormick, N. (2005). Rhetoric and the rule of law. A theory of legal reasoning. Oxford: Oxford University Press.

Mader, L. (1988). Experimentelle Gesetzgebung. Gesetzgebungstheorie und Rechtspolitik. Jahrbuch für Rechtssoziologie und Rechtstheorie, 13, 211-221.

Mäki, U. (2005). Models are experiments, experiments are models. Journal of Economic Methodology, 12(2), 303-315.

Mathis, K. (2011). Consequentialism in law. In K. Mathis (Ed.). Efficiency, sustainability, and justice to future generations (pp. 3-29). Doordrecht: Springer. 
Miscevic, N. (2018). Thought experiments in political philosophy. In M. T. Stuart, Y. J. H. Fehige \& J. R. Brown (Eds.). The Routledge companion to thought experiments (pp. 153170). Abingdon-New York: Routledge.

Mitchell, G. (2004). Case studies, counterfactuals, and causal explanations. University of Pennsylvania Law Review, 152(5), 1517-1608.

Moore, M. S. (2009). Causation and responsibility. Oxford: Oxford University Press.

Morand, C. A. (1993). L'obligation d'évaluer les effets des lois. In C. A. Morand (Ed.). L'évaluation législative et lois expérimentales (pp. 79-115). Aix en Provence: Presses Universitaires d'Aix Marseille.

Nersessian, N. J. (2018). Cognitive science, mental modeling, and thought experiments. In M. T. Stuart, Y. J. H. Fehige \& J. R. Brown (Eds.). The Routledge companion to thought experiments (pp. 309-326). Abingdon-New York: Routledge.

Norton, J. D. (1991). Thought experiments in Einstein's work. In T. Horowitz \& G. Massey (Eds.). Thought Experiments in Science and Philosophy (pp. 129-148). Lanham: Rowman and Littlefield.

O'Grady, C. G. (2011). The role of speculation in facial challenges. Arizona Law Review, 53, 867-911.

Parfit, D. (2011). On what matters (Vol. I). Oxford: Oxford University Press.

Posner, R. A. (1995). Overcoming law. Cambridge: Harvard University Press.

Posner, R. A. (1996). Pragmatic adjudication. Cardozo Law Review, 18, 1-20.

Posner, R. A. (2004). Legal pragmatism. Metaphilosophy, 35(1-2), 147-159.

Ranchordas, S. (2014). Constitutional sunsets and experimental legislation: A comparative perspective. Cheltenham: Edward Elgar.

Reiss, J. (2013). Genealogical thought experiments in economics. In M. Frappier, L. Meynell \& J. R. Brown (Eds.). Thought experiments in philosophy, science, and the arts (pp. 177190). New York: Routledge.

Reiss, J. (2018). Thought experiments as idealizations. In M. T. Stuart, Y. J. H. Fehige \& J. R. Brown (Eds.). The Routledge companion to thought experiments (pp. 469-483). Abingdon-New York: Routledge.

Rodrik, D. (2015). Economic rules. The rights and the wrongs of the dismal science. New York: W. W. Norton.

Schram, A. \& Ule, A. (Eds.) (2019). Handbook of research methods and applications in experimental economics. Cheltenham: Edward Elgar.

Shabas, M. (2018). Thought experiments in economics. In M. T. Stuart, Y. J. H. Fehige \& J. R. Brown (Eds.). The Routledge companion to thought experiments. Abingdon-New York: Routledge.

Sorensen, R. A. (1992). Thought experiments. New York: Oxford University Press.

Strassfeld, R. N. (1992). If . . .: Counterfactuals in the law. George Washington Law Review, 60, 339-416.

Stuart, M. T. (2016). Norton and the logic of thought experiments. Axiomathes, 26, 451-466.

Stuart, M. T. (2018). How thought experiments increase understanding. In M. T. Stuart, Y. J. H. Fehige \& J. R. Brown (Eds.). The Routledge companion to thought experiments (pp. 526-544). Abingdon-New York: Routledge.

Stuart, M. T. (2020). Thought experiments. In Glăveanu (Ed.). The Palgrave encyclopedia of the possible. Cham: Palgrave Macmillan.

Stuart, M. T., Fehige, Y. J. H. \& Brown, J. R. (Eds.) (2018). The Routledge companion to thought experiments. Abingdon-New York: Routledge.

Thoma, J. (2016). On the hidden thought experiments of economic theory. Philosophy of the Social Sciences, 46(2), 129-146.

Van Gestel, R. \& van Dijck, G. (2011). Better regulation through experimental legislation. European Public Law, 17(3), 539-553. 
Weinrib, E. J. (1989). Understanding tort law. Valparaiso University Law Review, 23(3), 485526.

Werner, P. \& Riedl, A. (2019). The role of experiments for policy design. In A. Schram \& A. Ule (Eds.). Handbook of research methods and applications in experimental economics (pp. 295-311). Cheltenham: Edward Elgar.

Wilson, J. (2016). Internal and external validity in thought experiments. Proceedings of the Aristotelian Society, 116(2), 127-152. 